\title{
Baseline survey: Summary report of district Upper Dir
}

Pakistan Initiative for Mothers and Newborns (PAIMAN)

Follow this and additional works at: https://knowledgecommons.popcouncil.org/departments_sbsr-rh

Part of the Family, Life Course, and Society Commons, and the Maternal and Child Health Commons How does access to this work benefit you? Let us know!

\section{Recommended Citation}

Pakistan Initiative for Mothers and Newborns (PAIMAN). 2006. "Baseline survey: Summary report of district Upper Dir." Islamabad: Population Council. 


\section{Baseline Survey \\ Summary Report}

District Upper Dir

This summary report presents some of the key findings of a 2005 baseline household survey in Upper Dir district, one of the ten districts in Pakistan that are the focus of the PAIMAN project. The Pakistan Initiative for Mothers and Newborns (PAIMAN) is a five-year project funded by the United States Agency for International Development (USAID). PAIMAN is committed to assist the Government of Pakistan in its implementation of the full spectrum of interventions necessary to address maternal and neonatal health $(\mathrm{MNH})$ issues. The PAIMAN district survey results are presented individually; the districts are: Rawalpindi, Jhelum, Khanewal and DG Khan in Punjab; Dadu and Sukkur in Sindh; Jaffarabad and Lasbela in Balochistan; and Upper Dir and Buner in North West Frontier Province.

PAIMAN has developed a monitoring and evaluation plan to ensure that the success of the project was properly ascertained, and that the appropriate lessons learned. PAIMAN conducted the baseline household survey in the ten districts in order to understand local MNH perceptions and practices. The study population included all currently married women of reproductive age (15-49 years) living in all urban and rural areas of the district. The sampling design was a stratified, systematic sample of households.

In Upper Dir, 835 women were interviewed, of whom 789 (94 percent) were rural. Fifteen percent of respondents were literate. On average, respondents had borne 4.2 children, of whom 3.9 were still living. 


\section{Knowledge,}

Attitude

\section{and Behavior}

Figure 1: Percentage of married women in Upper Dir who know at least 3 danger signs

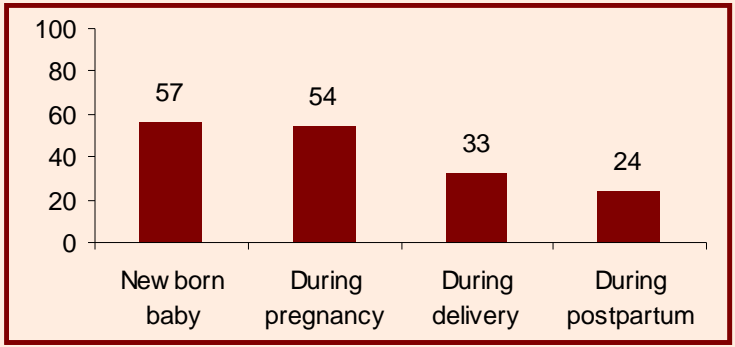

Figure 2: Percentage of married women in Upper Dir who received antenatal care, TT injections and iron folate during their last pregnancy

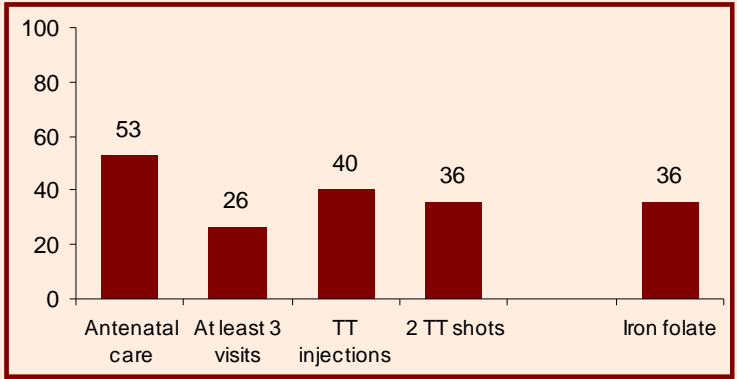

Figure 3: Percentage of married women in Upper Dir who received antenatal services during their antenatal visits, by type of services received

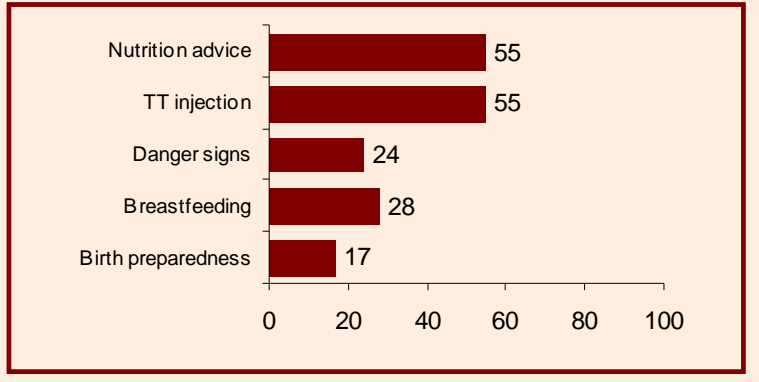

\section{Majority of Women Know Danger Signs Well}

\section{Knowledge of danger signs}

From figure 1, knowledge of danger signs on the part of married women varies between pregnancy, delivery, and postpartum period. More women know about danger signs in newborns and pregnancy than in delivery; even fewer know the danger signs in the postpartum period.

\section{Source of information regarding danger signs}

* Most receive information from district headquarter hospital.

* About one-third receive information primarily from friends and relatives.

* One-quarter of women receive information from BHU/RHC and the same proportion mention private health facilities.

* Very few mention community workers or electronic media as a primary source.

\section{Some Women Receive Antenatal Care}

* Over 88 percent consider it necessary for women to receive antenatal check-ups.

* One-third believe that an antenatal check-up should occur in the first three months of pregnancy.

* For their last delivery, 53 percent of pregnant women had an antenatal checkup (figure 2).

* More than one-third of pregnant women had TT injections during their last pregnancy; the same proportion took folate tablets.

\section{Components of antenatal check-up}

Figure 3 suggests that most women are not advised about preparing for emergencies.

* Two-thirds of pregnant women receive advice about nutrition

* Fifty-five percent were given information on TT shots and 28 percent on breastfeeding

* One-quarter were provided information about danger signs and 17 percent were given information on birth preparedness

\section{Most Women are Unprepared for Emergencies, and Most Deliver at Home}

\section{Preparedness for childbirth}

Many women appear to have made appropriate arrangements for delivery (figure 4), but most have not made arrangements for emergency funds or transport.

\section{Place of delivery and services}

* A majority (91 percent) agrees that delivery services should be obtained from skilled birth attendants.

* Data obtained on the births that occurred during the last three years (figure 5), show that 76 percent of women delivered their babies at home, while 23 percent delivered at a public or private hospital.

* Thirty-three percent of deliveries were conducted by a skilled birth attendant. 


\section{Delivery characteristics}

From figure 6, almost 9 in every 10 pregnancies result in a normal vaginal delivery. However, 4 percent of deliveries received medical intervention.

\section{Complications During Pregnancy and Childbirth are Common}

Nearly three-quarters of pregnant women in the district indicate they experienced a complication during their last pregnancy. Severe abdominal pain, severe headache, severe/prolonged vomiting and high fever were the complications most reported.

More than 57 percent of women report experiencing at least one complication during delivery. More than one-third of women experienced excruciatingly abnormal pain during their last delivery. Obstructed labour, fever, premature rupture of membranes, and excessive bleeding were among other reported complications. For many of these complications, women receive no care or inappropriate care.

\section{Postpartum and Newborn Care Need Attention}

\section{Postpartum check-up}

* For those who delivered their last baby at home, almost 86 percent did not receive any postnatal check-ups.

* Among those who go for postnatal care, only four percent go within 24 hours after childbirth.

\section{Immediate care of newborn}

* While more than one-third of the mothers (35 percent) report that their newborns were put with them immediately following delivery, many newborns are placed on either a piece of cloth ( 25 percent) or on a mattress (15 percent).

* Only four percent indicate that their newborns are placed on the floor immediately after delivery.

- Sixty-two percent of newborn are given a bath within one hour of birth; only 25 percent are bathed after the recommended six hours.

\section{Colostrum and breastfeeding}

Over 97 percent of mothers indicate that they breastfeed their child. Of those who breastfed their newborns, 15 percent started breastfeeding within the first hour after birth. Seventy-one percent of newborn were given colostrum.

\section{Neonatal care}

* One-fourth of mothers report that their newborn was examined by a skilled provider soon after birth.

- Immediately after birth, weak or no cry were the most common problems reported. Jaundice and redness on cord with discharge were the most commonly noted complications in newborns within the first seven days.

* The most common choices for newborns' treatments are private health facilities and district headquarters hospitals.

* Seventeen percent fail to seek treatment when symptoms of a complication are seen in their newborns.

\section{Clean Delivery Practices}

Respondents who delivered their last child at home report the following delivery practices:

* TBA did not wash her hands with soap for 38 percent of deliveries.

* TBA did not use a new blade for cutting the cord for at least two-thirds of newborns. Scissors and knives were reportedly used by TBAs.

* A new piece of thread was used for tying the cord for 88 percent of the newborns.

Figure 4: Percentage of married women in Upper Dir who made delivery arrangements by type of arrangements

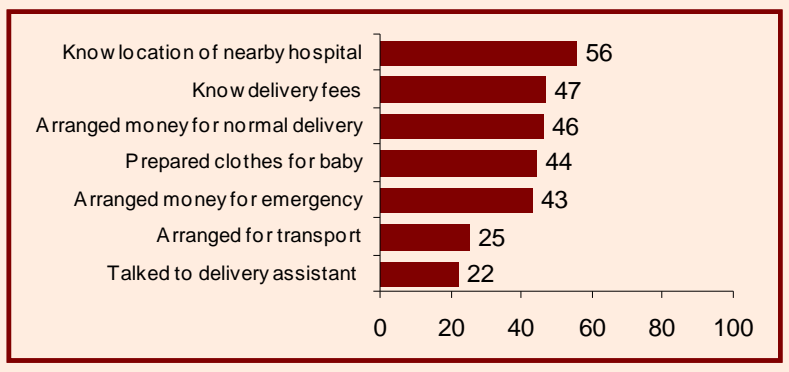

Figure 5: Percentage of married women in Upper Dir who gave birth in the preceding three years, by place of delivery.

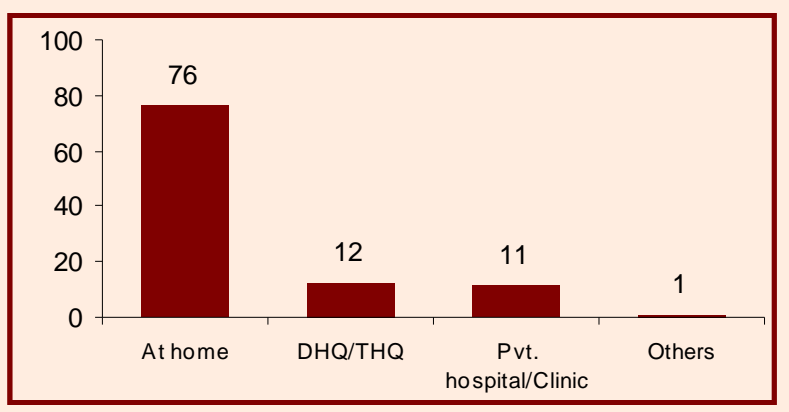

Figure 6: Percentage of married women in Upper Dir who gave birth, by the type of last delivery

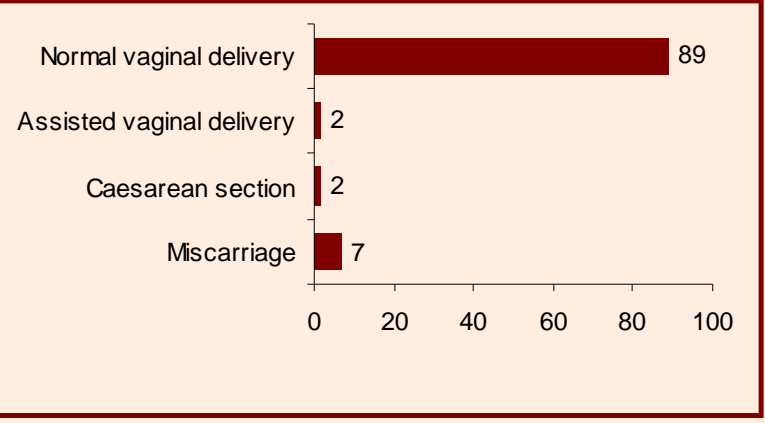




\section{Three Delays}

Delays in deciding to seek care, in reaching adequate health facilities, and in receiving appropriate care at health facilities lead to most maternal deaths.

\section{First delay: decisions must be made quickly}

- Half of the women are prepared for delivery (figure 4) and know about danger signs well (figure 1), but many other women are not adequately prepared or aware. Those in the latter category are not well placed to make emergency decisions.

* Women report their husbands (44 percent) or other family members (41 percent) make decisions for emergency delivery.

\section{Second delay: transport must be at hand and available}

* Of those seeking care for delivery complications, 54 percent call service provider to their home, one-third use private transport and 7 percent use their own vehicle to reach the health facility.

* The average waiting time for transport is 60 minutes; transport averages an additional 60 minutes to reach the desired facility. By that time, potentially fatal complications may no longer be treatable.

\section{Third delay: emergency services must be ready}

* After reaching the health facility, 88 percent of women report receiving services within 30 minutes. The median waiting time was 15 minutes.

* Appropriateness and quality of those services could not be ascertained.

\section{Access to media}

About 18 percent of households in Upper Dir own television and 58 percent own radio. However only 9 percent of women watch television and 18 percent listen to radio. With few women reading newspapers, only a little over one-fourth of women have access to any form of mass media (see figure 7).

Figure 7: Percentage of married women in Upper Dir who have access to mass media, by type of media

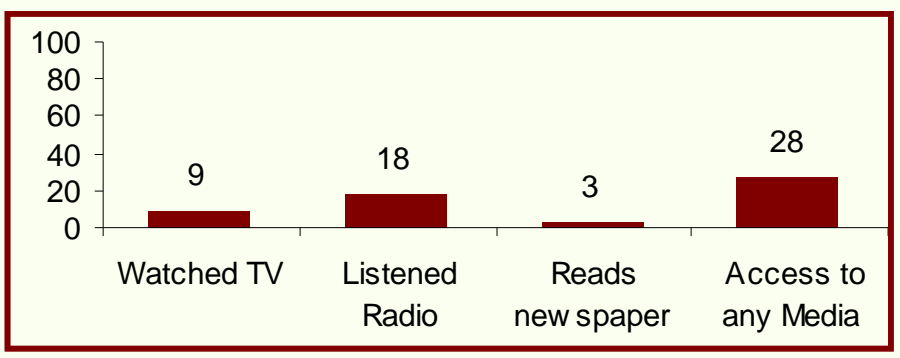

\section{Many pregnancies are unwanted}

* Sixteen percent of respondents were using family planning at the time of the study. About threefourths of these (12 percent) were using pills or injections. Thirty-one percent of respondents reported their intent to use family planning in the future.

* Only 7 percent of respondents reported that their last pregnancy was unwanted or mistimed. If unwanted pregnancies could be prevented in the first place, the attendant morbidity and mortality could be avoided.

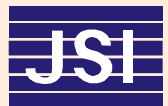

JSI Research \& Training Institute, Inc.

CA \# 391-A-00-05-01037-00 project is funded by the United States Agency for International Development

and implemented by JSI Research \& Training Institute, inc. in conjunction with Aga Khan University, Contech International,

Greenstar Social Marketing, Johns Hopkins University/CCP, PAVHNA, The Population Council, and Save the Children USA. 